\title{
Lung structure-function correlation in patients with primary ciliary dyskinesia
}

\author{
Mieke Boon, ${ }^{1}$ Francois L Vermeulen, ${ }^{1}$ Willem Gysemans, ${ }^{1}$ Marijke Proesmans, ${ }^{1}$ \\ Mark Jorissen, ${ }^{2}$ Kris De Boeck ${ }^{1}$
}

\begin{abstract}
- Additional material is
published online only. To view please visit the journal online (http://dx.doi.org/10.1136/ thoraxjnl-2014-206578).

1 Department of Pediatrics, Pediatric Pulmonology, University Hospital

Gasthuisberg, Leuven, Belgium ${ }^{2}$ Department of

Otorhinolaryngology, Head and Neck Surgery, University Hospital Gasthuisberg Leuven, Leuven, Belgium
\end{abstract}

\section{Correspondence to}

Dr Mieke Boon, Department of Pediatrics, Pediatric

Pulmonology, University

Hospital Leuven, Herestraat 49 Leuven 3000, Belgium; mieke. boon@uzleuven.be

Part of the results in this study have been previously reported in the form of an abstract.

Received 13 November 2014 Revised 13 January 2015 Accepted 18 January 2015 Published Online First 11 February 2015

\section{ABSTRACT \\ Background Primary ciliary dyskinesia (PCD) is a rare} disease, characterised by chronic airway infection. In cystic fibrosis, $\mathrm{FEV}_{1}$ is insensitive to detect patients with structural damage, and Lung Clearance Index $(\mathrm{LCl})$ was proposed as a better marker of early lung damage. In $P C D$, the relationship between functional and structural abnormalities has been less studied. We aimed to reexamine this in a cohort of children and adults with mild to moderate PCD.

Methods Thirty-eight patients with PCD (5.225.0 years) and 70 healthy controls (4.4-25.8 years) were recruited to compare $\mathrm{LCl}$, measured by $\mathrm{N}_{2}$ multiple breath washout and $\mathrm{FEV}_{1}$ in a prospective observational trial. In a subset of 30 patients who underwent chest imaging, structural abnormalities were evaluated with cystic fibrosis computed tomography (CFCT) scores.

Results $\mathrm{LCl}$ was abnormal in 28 of 38 patients and a moderate correlation was observed between $\mathrm{LCl}$ and $\mathrm{FEV}_{1}(\mathrm{r}=-0.519, \mathrm{p}=0.001)$. Moreover, $\mathrm{LCl}$ correlated well with CFCT total score $(r=0.800, p<0.001)$ and also with subscores for airway wall thickening $(r=0.809, p<0.001)$, mucus plugging $(r=0.720$, $p<0.001)$ and bronchiectasis $(r=0.494, p<0.001)$. Concordance was seen between $\mathrm{LCl}$ and CFCT in 25 of $30(83 \%)$ patients, but between $\mathrm{FEV}_{1}$ and CFCT in only 16 of $30(53 \%)$ patients. $\mathrm{LCl}$ was more sensitive $(90.9 \%, 95 \% \mathrm{Cl} 70.8$ to 98.6$)$ to detect patients with structural abnormalities than $\mathrm{FEV}_{1}(36.4 \%, 95 \% \mathrm{Cl}$ 17.2 to 59.3 ).

Conclusions We demonstrated that measuring $\mathrm{LCl}$ in patients with PCD is of clinical relevance; it was more frequently abnormal than $\mathrm{FEV}_{1}$, correlated well with CFCT and was more sensitive than FEV 1 to detect patients with structural abnormalities.

\section{INTRODUCTION}

\section{SLinked}

- http://dx.doi.org/10.1136/ thoraxjnl-2015-206822

CrossMark

To cite: Boon $M$,

Vermeulen FL, Gysemans W, et al. Thorax 2015;70: 339-345.
Primary ciliary dyskinesia (PCD) is a rare disease, characterised by recurrent upper and lower respiratory tract infections and an increased incidence of situs inversus and male infertility. ${ }^{2} 3$ The diagnosis is often difficult and delayed. ${ }^{4}$ Disease severity ranges from mild respiratory symptoms to chronic obstructive lung disease and respiratory failure requiring lung transplantation. Radiological examinations show bronchiectasis, atelectasis, mucus plugging, bronchiolitis and air trapping as the main findings. ${ }^{5}$ Therapy is supportive and mainly consists of chest physiotherapy to enhance mucociliary clearance and antibiotics to treat acute and chronic infections. $^{2}$

\section{Key messages}

What is the key question?

- Is there really no correlation between structure and function in patients with primary ciliary dyskinesia (PCD)?

\section{What is the bottom line?}

- In patients with PCD, Lung Clearance Index (LCI) correlates with $\mathrm{FEV}_{1}$ and imaging parameters, but $\mathrm{LCl}$ is more sensitive than $\mathrm{FEV}_{1}$ to detect patients with high resolution computed tomography (HRCT) abnormalities.

\section{Why read on?}

- This study sheds a new light on the correlation between $\mathrm{LCl}_{1} \mathrm{FEV}_{1}$ and chest $\mathrm{CT}$ abnormalities in patients with $P C D$.

Compared with cystic fibrosis (CF), the natural history of PCD is much less known. Early studies suggested relatively stable lung disease without significant lung function decline. ${ }^{7} 8$ A more recent study showed stable $\mathrm{FEV}_{1}$ in $57 \%$ over a time span of 5-30 years, improvement of $\mathrm{FEV}_{1}$ in $10 \%$ and a progressive decline of lung function in $34 \%$ of the patients. ${ }^{9}$ Still, mean $\mathrm{FEV}_{1}$ is already abnormal at the age of 6 years, demonstrating that lung damage starts early. ${ }^{10}$

In patients with $\mathrm{PCD}, \mathrm{FEV}_{1}$ correlates with chest CT scores, ${ }^{11}$ but as in CF, lung structural damage was shown to progress, despite little change in lung function. ${ }^{12}$ However, because of the associated radiation burden, even low-dose high resolution computed tomography (HRCTs) are not an option for close follow-up. ${ }^{13}$

The past decade has seen a revival of measuring ventilation inhomogeneity by assessing multiple breath washout (MBW) using an inert gas. The Lung Clearance Index (LCI), the number of lung turnovers needed to reduce the concentration of an inert gas to one-fortieth of the starting value, has become the most used parameter. ${ }^{14}$ In CF, LCI is more sensitive than $\mathrm{FEV}_{1}$ to detect patients with structural abnormalities on chest CT. ${ }^{15} 16$ Therefore, LCI has been proposed as an outcome parameter in CF clinical trials. ${ }^{17}$ Also, a recent study in adults with non-CF bronchiectasis demonstrated the value of LCI in this population: just as in CF, it was more sensitive than $\mathrm{FEV}_{1}$ to detect patients with structural abnormalities on chest $\mathrm{CT}$. $^{18}$ 
Two studies demonstrated that LCI was abnormal in patients with PCD, compared with healthy controls (HCs). ${ }^{19} 20$ In contrast to what is known in CF, these studies failed to find a correlation between LCI and $\mathrm{FEV}_{1}$. A possible disconnect between large and small airway disease was put forward as hypothesis. ${ }^{19}{ }^{20}$ One of these studies also assessed structural abnormalities on chest CT. No correlation between structure and function was found, but only adults with rather advanced disease were included. ${ }^{20}$ Of course, to find a correlation, studying a relatively wide disease variability is needed and the authors already alluded to that shortcoming.

Therefore, the aim of our study was to re-examine the relationship between MBW parameters, spirometry and chest imaging in children and adults with PCD and mild to moderate disease.

\section{METHODS \\ Subjects}

Patients with PCD were recruited from the University Hospital of Leuven PCD follow-up clinic for a prospective observational trial of MBW measurement, spirometry and chest imaging between May 2011 and September 2014. In all patients, the diagnosis had been confirmed by functional and structural evaluation of the motile cilia on a nasal punch biopsy, including a cell culture system to exclude secondary defects. ${ }^{21}$ Patients were only included when they were clinically stable (no change in cough or sputum, no fever, no change in therapy for a period of at least 2 weeks, change in $\mathrm{FEV}_{1}<10 \%$ since the last measurement).

HCs were recruited in the same time period by advertising. Persons with a history of prematurity, asthma, allergy or recurrent respiratory symptoms were excluded. Spirometry and MBW were performed in all.

Height, weight and Body Mass Index were expressed as z-scores according to the Flemish reference equations. ${ }^{22}$

All patients or parents of patients gave written informed consent before participation.

\section{Multiple breath washout}

Nitrogen $\left(\mathrm{N}_{2}\right)$ MBW measurement was performed, using an Exhalyzer D (EcoMedics, Duernten, Switzerland; Spiroware V.3.2 software). Oxygen was administered to obtain washout of nitrogen. LCI is calculated as the cumulative expired volume divided by the functional residual volume (FRC) and represents the number of lung volume turnovers needed to clear the lungs from nitrogen to one-fortieth of the initial concentration. $S_{\text {cond }}$ and $S_{\text {acin }}$ are both derived from the concentration normalised slope of phase III $\left(\mathrm{S}_{\mathrm{nIII}}\right)$ of exhaled breaths. $\mathrm{S}_{\text {cond }}$ is an index of convectiondependent inhomogeneity and is calculated as the increase in measured $S_{\text {nIII }}$ per unit turnover between 1.5 and 6 turnovers. $S_{\text {acin }}$ is an index of diffusion convection-interaction-dependent inhomogeneity and is calculated from the $S_{\text {nIII }}$ slope of the first breath. To normalise for age, $S_{\text {cond }}$ and $S_{\text {acin }}$ were both multiplied by $V_{T}$ (tidal volume), as proposed in the MBW consensus guidelines. ${ }^{23}$

At least two technically acceptable measurements per patient were performed. In accordance with the recent guidelines on $\mathrm{MBW}^{23}$ those with significant leaks or sighs and those with LCI or FRC variability $>25 \%$ were excluded. The mean LCI of at least two measurements was used.

\section{Spirometry}

Spirometry was performed according to the American Thoracic Society/European Respiratory Society (ATS/ERS) guidelines. ${ }^{24}$ $\mathrm{FEV}_{1}, \mathrm{FVC}, \mathrm{FEV}_{1} / \mathrm{FVC}$ and $\mathrm{FEF}_{25-75}$ were expressed as z-scores according to the reference equations from the Global Lung Function Initiative. $^{25} \mathrm{~A}$ z-score below -1.96 was defined as abnormal. Spirometry was performed on the same day as MBW and always after MBW.

\section{Chest CT scan}

In our multidisciplinary PCD outpatient clinic protocol, a routine chest HRCT is performed every 5 years. Patients with a chest HRCT within 1 year of the MBW measurement, and without exacerbations (defined as subjective change in cough or sputum) needing change in therapy (adding or stopping either intravenous, oral or nebulised antibiotics or mucolytics), were included for this part of the study. Thirty patients were included for MBW, spirometry and chest CT. In 20 patients, HRCT and lung function were measured on the same day, in six patients the time interval was $<2$ months, in four patients the interval was $>2$ months. In all patients, the clinical status had remained stable in that time window.

A cystic fibrosis computed tomography (CFCT) score, which is a variant of the modified Brody Score, was used to quantify specific abnormalities on chest $\mathrm{CT}^{26}$ : severity and extent of bronchiectasis, severity and extent of airway wall thickening, mucus plugging in central and peripheral airways and parenchymal abnormalities (consolidation, atelectasis, cysts and ground glass opacities) were scored per lobe on inspiratory CT scans and air trapping on expiratory chest CT scans. The lingula was considered as a separate lobe. More details on CFCT are available in online supplementary file 1 . The chest CT scans were scored by two scorers who had successfully completed the training module of the corelab LungAnalysis (Rotterdam, The Netherlands). The second scorer rated a subset of the chest CT scans, and interobserver and intraobserver variability for the first scorer were good (see online supplementary file 2). The theoretical maximum score is 243. In practice, the maximum score cannot exceed 207, since a lobe cannot have more than two-third involvement from all abnormalities at the same time. CFCT score was expressed as percentage of this maximum score of 207. For scans without expiratory images $(n=6)$, the maximum score for air trapping was subtracted from the maximum score. A total CFCT score $>5 \%$ was defined as abnormal. ${ }^{26}$

\section{Statistics}

LCI, $\mathrm{S}_{\text {cond }} \times \mathrm{V}_{\mathrm{T}}$ and $\mathrm{S}_{\text {acin }} \times \mathrm{V}_{\mathrm{T}}$ were normally distributed in HCs and therefore $\mathrm{z}$-scores for MBW parameters could be calculated reliably. A z-score $>1.96$ was defined as abnormal.

For the PCD group only non-parametric tests were used. The data were presented as medians and IQRs. For comparison between groups, Mann-Whitney test was used for continuous variables, $\chi^{2}$ for categorical variables. Correlations were described with Spearman's rank correlation coefficient (r). A correlation of $>0.7$ was considered as strong, between 0.3 and 0.7 as moderate and $<0.3$ as weak. A p value of $<0.05$ was defined as statistically significant. SPSS V.21.0 (IBM, Armonk, New York, USA) was used for statistical analyses.

\section{RESULTS}

\section{Subjects}

Thirty-nine patients with PCD (aged 5.2-25.0 years) and 75 HCs (aged 4.4-25.8 years) were recruited. One patient with PCD was excluded because of irregular breathing pattern and leaks during MBW, five HCs were excluded due to leaks $(n=2)$, $>25 \%$ variability of FRC $(n=1)$, intolerance of the MBW measurement $(n=1)$ and inability to perform spirometry $(n=1)$. The intravisit repeatability of LCI was good and did not differ 
between patients with PCD and HCs; the median coefficient of variation was 3.5 for $\mathrm{HCs}$ versus 3.1 for patients with $\mathrm{PCD}$ $(p=0.469)$. General characteristics of HCs and PCD are presented in table 1. As reported previously, patients with PCD were significantly shorter than HCs $(\mathrm{p}<0.001) .{ }^{10}$

Thirty patients with PCD were included in the chest HRCT substudy. Two patients had undergone lobectomy.

\section{MBW parameters and spirometry in PCD and HCs}

All parameters differed between patients with PCD (total group as well as CFCT subgroup) and HCs (table 2). Online supplementary file 3 shows that the results for our control group are very similar to those of the control group reported by Houltz et $a l,{ }^{27}$ who used a similar equipment and protocol.

\section{MBW parameters versus spirometry}

In PCD, LCI z-score ranged from -0.87 to 19.3 and 28 of 38 (73\%) had an abnormal LCI. There was a moderate negative correlation between LCI z-score and $\mathrm{FEV}_{1}$ z-score $(\mathrm{r}=-0.519$, $\mathrm{p}=0.001)$. Figure 1 shows that 10 of $38(26 \%)$ patients had normal LCI z-score and normal FEV $_{1}$ z-score, 10 of 38 (26\%) had abnormal LCI and abnormal $\mathrm{FEV}_{1}$ z-score and 18 of 38 (47\%) patients had normal $\mathrm{FEV}_{1}$ but abnormal LCI z-score. There was also a moderate negative correlation between LCI z-score and $\mathrm{FEV}_{1} / \mathrm{FVC} \mathrm{z}$-score $(\mathrm{r}=-0.434, \mathrm{p}=0.006)$ as well as $\mathrm{FEF}_{25-75} \mathrm{z}$-score $(\mathrm{r}=-0.450, \mathrm{p}=0.005)$.

In the HCs, there was a weak correlation between LCI z-score and $\mathrm{FEV}_{1} \mathrm{z}$-score $(\mathrm{r}=-0.286, \mathrm{p}=0.016), \mathrm{FEF}_{25-75} \mathrm{z}$-score $(\mathrm{r}=$ $-0.259, \quad \mathrm{p}=0.03)$, but not $\mathrm{FEV}_{1} / \mathrm{FVC}$ z-score $(\mathrm{r}=-0.004$, $\mathrm{p}=0.977)$.

$\mathrm{FEV}_{1}$ did not correlate with age in patients with PCD $(\mathrm{r}=-0.122$, $\mathrm{p}=0.465$; figure $2 \mathrm{~A}$ ); however, it is clear from the graph that mean $\mathrm{FEV}_{1}$ is lower in PCD compared with HCs. Although LCI increases with age in patients with PCD, the correlation between LCI and age is not significant $(r=0.124, p=0.457$; figure $2 \mathrm{~B})$. MBW and spirometry parameters did not correlate with age either at diagnosis or since diagnosis.

\section{MBW parameters versus CFCT}

Total CFCT scores ranged from $1.9 \%$ to $26.8 \%$ (median $8.4 \%$ ), and 22 of $30(73 \%)$ had an abnormal CFCT score. For detailed information on the results of CFCT, see the online supplementary file 4 . We found a strong correlation between LCI z-score and total CFCT score $(r=0.800, p<0.001$; figure $3 \mathrm{~A})$, as well as subscores for airway wall thickening $(\mathrm{r}=0.809, \mathrm{p}<0.001)$ and mucus plugging (table 3$)(\mathrm{r}=0.720, \mathrm{p}<0.001)$, and a moderate correlation between LCI z-score and subscore for bronchiectasis $(r=0.494, p<0.001)$. Of the CFCT subscores, the airway wall thickening subscore had the widest span between patients (see online supplementary file 4). There was a moderate correlation between $\mathrm{S}_{\text {acin }} \times \mathrm{V}_{\mathrm{T}} \quad(\mathrm{r}=0.361, \quad \mathrm{p}=0.05)$, but not $\mathrm{S}_{\text {cond }} \times \mathrm{V}_{\mathrm{T}}$ $(\mathrm{r}=0.276, \mathrm{p}=0.139)$ and total CFCT score.

There was a moderate correlation between total CFCT score and $\mathrm{FEV}_{1} \mathrm{z}$-score $(\mathrm{r}=-0.632, \mathrm{p}<0.001$; figure $3 \mathrm{~B}), \mathrm{FEF}_{25-75}$ $(\mathrm{r}=-0.463, \mathrm{p}=0.01)$, but not $\mathrm{FEV}_{1} / \mathrm{FVC}$. Also, the airway wall thickening subscore correlated with all lung function parameters (table 3).

There was a moderate correlation between total CFCT score and age $(r=0.376, p=0.041$; figure $2 \mathrm{C})$, but not age at diagnosis $(r=0.245, p=0.193)$ or time since diagnosis $(r=0.084$, $\mathrm{p}=0.658)$.

\section{Concordance between function and structure measurements}

LCI and CFCT were concordant in 25 of 30 (83\%) patients (both normal in five and both abnormal in 20). In two patients, LCI was abnormal and CFCT was normal and in three patients, CFCT was normal and LCI was abnormal.

CFCT and $\mathrm{FEV}_{1}$ were concordant in 16 of 30 (53\%) of patients only. LCI and $\mathrm{FEV}_{1}$ were concordant in 20 of 38 $(53 \%)$ in the total group and in 15 of $30(50 \%)$ in the CFCT subgroup only.

The sensitivity of LCI to detect patients with abnormal CFCT was $90.9 \%$ (95\% CI $70.8 \%$ to $98.6 \%$ ) and was significantly higher than that of $\mathrm{FEV}_{1}(36.4 \%, 95 \%$ CI 17.2 to 59.3). Positive predictive value and negative predictive value to detect or exclude abnormalities on the CFCT score were $87 \%$ and $71 \%$ for LCI and $100 \%$ and $36 \%$ for $\mathrm{FEV}_{1}$, respectively.

\section{DISCUSSION}

This single centre, prospective cross-sectional study in patients with PCD demonstrated a strong correlation between LCI and abnormalities on chest CT, quantified by the CFCT score. The correlation was significant for the total CFCT score but also for the subscores of airway wall thickening, mucus plugging and bronchiectasis. LCI z-score also correlated with $\mathrm{FEV}_{1}$ but the sensitivity to detect structural lung abnormalities was much higher for LCI than for $\mathrm{FEV}_{1}$. The feasibility and repeatability of LCI was good in patients with PCD.

$\mathrm{S}_{\text {cond }} \times \mathrm{V}_{\mathrm{T}}$ and $\mathrm{S}_{\text {acin }} \times \mathrm{V}_{\mathrm{T}}$, both markers of small airways disease, were abnormal in PCD compared with HCs, confirming that PCD causes small airways disease. There was a moderate correlation between $S_{\text {acin }} \times V_{T}$ (a measure of diffusion-convection-dependent

Table 1 Baseline characteristics in HCs and patients with PCD

\begin{tabular}{|c|c|c|c|c|c|}
\hline & $\begin{array}{l}\text { HCs } \\
(n=70)\end{array}$ & $\begin{array}{l}\text { PCD } \\
(n=38)\end{array}$ & $\begin{array}{l}\text { PCD with chest } \\
\text { CT scan } \\
(n=30)\end{array}$ & $\begin{array}{l}\text { p Value for } \\
\text { comparison } \\
\text { HCs vs all PCD* }\end{array}$ & $\begin{array}{l}p \text { Value for } \\
\text { comparison } H C S \text { vs PCD } \\
\text { with chest } \mathrm{CT}^{*}\end{array}$ \\
\hline Male/female & $28 / 42$ & $13 / 25$ & $12 / 18$ & 0.679 & 0.676 \\
\hline Age (years) $\dagger$ & $13.9(10.3$ to 19.9$)$ & 16.1 (11.1 to 19.6$)$ & $15.3(10.4$ to 18.0$)$ & 0.202 & 1.000 \\
\hline Age at diagnosis (years) $\dagger$ & NA & $4.9(1.2$ to 9.6$)$ & $4.9(1.0$ to 9.2$)$ & NA & NA \\
\hline Time since diagnosis (years) $\dagger$ & NA & $9.4(5.0$ to 14.9$)$ & 8.9 (4.8 to 14.8$)$ & NA & NA \\
\hline Weight z-scoret & $0.10(-0.44$ to 0.66$)$ & $-0.27(-0.89$ to 0.38$)$ & $-0.54(-1.17$ to 0.23$)$ & 0.047 & 0.007 \\
\hline Height z-scoret & $0.34(-0.34$ to 1.05$)$ & $-0.35(-1.21$ to 0.45$)$ & $-0.26(-1.19$ to 0.49$)$ & $<0.001$ & 0.004 \\
\hline BMI z-scoret & $-0.18(-0.75$ to 0.40$)$ & $-0.11(-0.93$ to 0.46$)$ & $-0.36(-1.00$ to 0.23$)$ & 0.946 & 0.274 \\
\hline
\end{tabular}


Table 2 Spirometry and MBW parameters in HCs and PCD

\begin{tabular}{|c|c|c|c|c|c|}
\hline & $\begin{array}{l}\text { HCs } \\
(n=70)\end{array}$ & $\begin{array}{l}P C D \\
(n=38)\end{array}$ & $\begin{array}{l}\text { PCD with } \\
\text { chest CT scan } \\
(n=30)\end{array}$ & $\begin{array}{l}\text { p Value for comparison } \\
\text { HCs vs all PCD* }\end{array}$ & $\begin{array}{l}\text { p Value for comparison } \\
\text { HCs vs } P C D \text { with chest } C^{*}\end{array}$ \\
\hline $\mathrm{FEV}_{1} \mathrm{z}$-score & $0.15(-0.46$ to 0.64$)$ & $-1.54(-2.1$ to -0.43$)$ & $-1.60(-2.11$ to -0.33$)$ & $<0.001$ & $<0.001$ \\
\hline $\mathrm{FEV}_{1} / \mathrm{FVC}$ z-score & $-0.16(-0.91$ to 0.40$)$ & $-1.52(-2.20$ to -1.01$)$ & $-1.62(-2.10$ to -1.15$)$ & $<0.001$ & $<0.001$ \\
\hline $\mathrm{FEF}_{25-75} \mathrm{z}$-score & $-0.39(-0.91$ to 0.42$)$ & $-1.99(-2.68$ to -0.61$)$ & $-2.18(-2.68$ to -1.28$)$ & $<0.001$ & $<0.001$ \\
\hline $\mathrm{LCl}$ & 7.1 (6.7 to 7.5$)$ & 9.48 (8.28 to 10.92$)$ & 9.48 (8.42 to 11.59$)$ & $<0.001$ & $<0.001$ \\
\hline LCl z-score & $0.17(-0.54$ to 0.67$)$ & 3.58 (1.84 to 5.70$)$ & 3.58 (2.03 to 6.69$)$ & $<0.001$ & $<0.001$ \\
\hline $\mathrm{S}_{\text {cond }} \times \mathrm{V}_{\mathrm{T}}$ & 0.011 (0.006 to 0.018$)$ & 0.057 (0.036 to 0.078$)$ & $0.060(0.036$ to 0.080$)$ & $<0.001$ & $<0.001$ \\
\hline $\mathrm{S}_{\text {cond }} \times \mathrm{V}_{\mathrm{T}} \mathrm{Z}$-score & $-0.21(-0.74$ to 0.55$)$ & $4.68(2.45$ to 6.90$)$ & 4.93 (2.45 to 7.12 ) & $<0.001$ & $<0.001$ \\
\hline $\mathrm{S}_{\mathrm{acin}} \times \mathrm{V}_{\mathrm{T}}$ & $0.044(0.034$ to 0.063$)$ & $0.079(0.034$ to 0.116$)$ & 0.079 (0.036 to 0.116$)$ & 0.009 & 0.005 \\
\hline $\mathrm{S}_{\mathrm{acin}} \times \mathrm{V}_{\mathrm{T}} \mathrm{z}$-score & $-0.27(-0.65$ to 0.49$)$ & 1.17 (-0.64 to 2.58$)$ & 1.11 (-0.58 to 2.50$)$ & 0.009 & 0.005 \\
\hline
\end{tabular}

ventilation inhomogeneity in the acinar airways) and total chest CFCT score. This confirms that chest CFCT can reliably detect small airway pathology. However, the clinical significance of abnormal $S_{\text {nIII }}$ slope parameters has to be further explored.

The findings in our study differ from previous results. Several reasons can explain these differences.

In the current study, we used $\mathrm{N}_{2}$ as tracer gas for MBW rather than $\mathrm{SF}_{6}$ that was used in previous studies and has been banned in several countries. The diffusion rate of a gas is inversely proportional to the square root of the molar mass. $\mathrm{N}_{2}$ (molar mass $28 \mathrm{~g} / \mathrm{mol}$ ) is much lighter than $\mathrm{SF}_{6}$ (molar mass $146 \mathrm{~g} / \mathrm{mol}$ ) and therefore the diffusion-convection front is located more proximal for $\mathrm{N}_{2}$ compared with $\mathrm{SF}_{6}{ }^{23}$ Differences in LCI have been demonstrated when different tracer gases are used: it was shown that LCI measured by $\mathrm{N}_{2}$ washout is higher than using $\mathrm{SF}_{6}$ washout, and that there is a bias towards higher LCI values. ${ }^{28}$

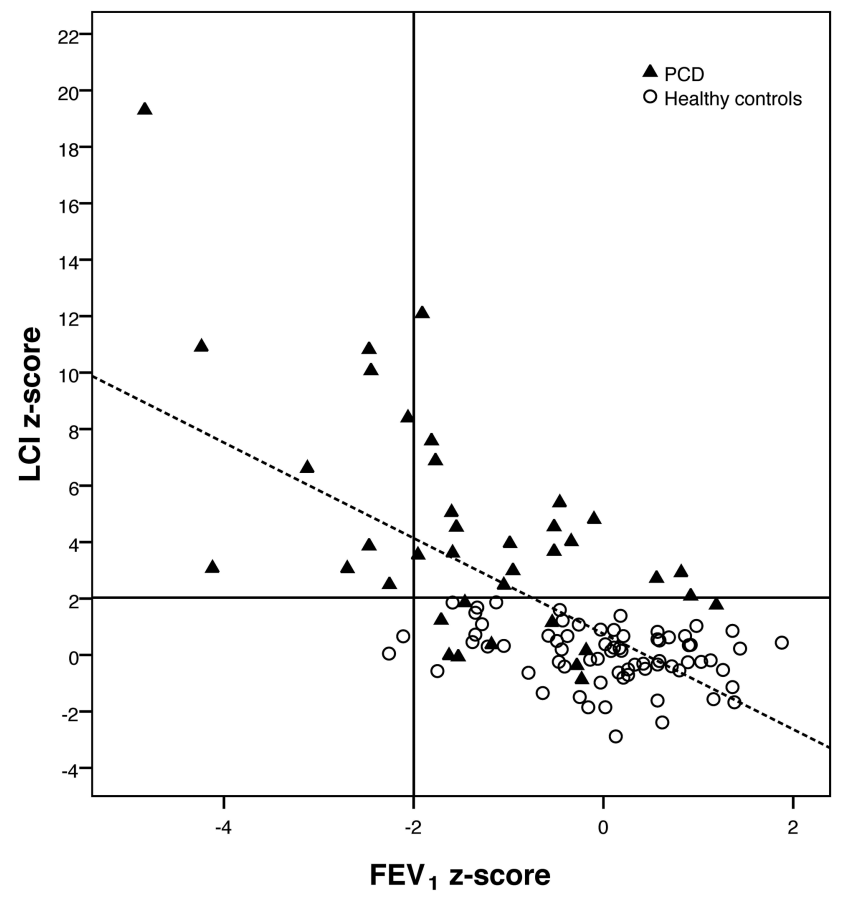

Figure 1 Correlation between $\mathrm{LCl}$ z-score and $\mathrm{FEV}_{1}$ z-score. $\mathrm{LCl}$, Lung Clearance Index; PCD, primary ciliary dyskinesia.
$\mathrm{SF}_{6}$ may not reach very poorly ventilated regions during washin, in contrast with $\mathrm{N}_{2}$, that is present in the environment and is therefore entirely washed in. Washout of these poorly ventilated regions may increase LCI measured during $\mathrm{N}_{2} \mathrm{MBW}$. Moreover, $\mathrm{N}_{2}$ is excreted by the tissues in very low amounts, which may also influence LCI. However, guidelines on MBW measurement do not recommend correction for tissue $\mathrm{N}_{2} \cdot{ }^{23}$ Because of higher values, it can be speculated that the discriminative power is higher for LCI measured by $\mathrm{N}_{2}$ washout than for LCI measured by $\mathrm{SF}_{6}$ washout. To obtain valid data with this newer technique, we included an HCs group, because reliable reference values for $\mathrm{N}_{2}$ washout were not yet available at the time of the study. ${ }^{23}$

Next, a type II error due to small sample size is not excluded, as already mentioned by Rowan et al. ${ }^{29}$ The current study has the largest sample size and therefore has the best power (38 patients vs $27^{19}$ and $33^{20}$ for the comparison between MBW and $\mathrm{FEV}_{1}$ and 30 patients vs $21^{20}$ concerning MBW and CT data). Moreover, the correlation between LCI and FEV 1 in the study by Irving et $a l^{30}$ was only marginally non-significant with a $\mathrm{p}$ value of 0.083 .

There are differences in the study populations: for the structure-function correlation, we studied children and adults with mild to moderate disease. Irving et al only studied adults with rather advanced disease with a median $\mathrm{FEV}_{1}$ of $-2.98 \mathrm{z}$-score, a limitation that they point out as one of the weaknesses of their study. In our study, median $\mathrm{FEV}_{1}$ was -1.54 z-score. Indeed, to reliably conclude about a significant correlation, a range in severities must be included in the sample. Data for comparison of LCI with CT in patients with mild to severe disease are now available for $\mathrm{CF}^{1620}$ and non-CF bronchiectasis, ${ }^{18} 30$ and we are confident that our data can fill the gap for data on mild to moderate disease in PCD.

Next, the CT scoring methods differ between our study and that of Irving et al. The modified individual feature CT score used by Irving has been reported before, ${ }^{31}$ but differs in many aspects from the CFCT score. Although the subscores of the individual feature score correlated well with the Brody subscores (except for airway trapping), they are not interchangeable. Moreover, the authors found a significant correlation between total Brody score and $\mathrm{FEV}_{1}$, but not between the total individual feature score and $\mathrm{FEV}_{1}$. In addition, the much lower number (21 vs 30 ) limits the possibility of finding a correlation.

Irving $e t a l^{20}$ as well as Green $e t a l^{19}$ report a significant correlation between LCI and $\mathrm{FEF}_{25-75} \mathrm{z}$-score. Green et al also 

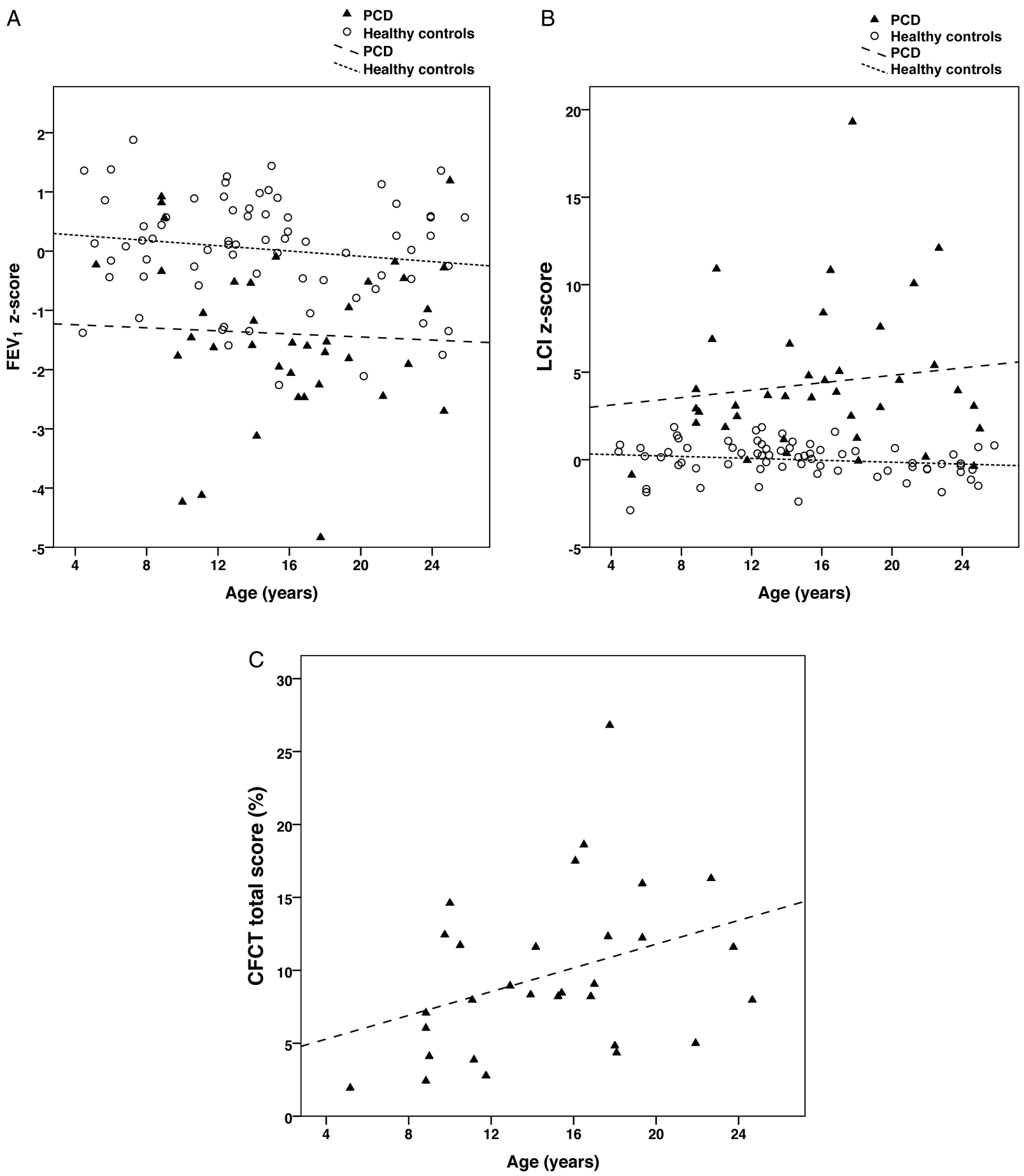

Figure 2 Correlation between $\mathrm{FEV}_{1}$ z-score (A), LCl z-score (B) and total CFCT score (\%; C) and age. LCl, Lung Clearance Index; PCD, primary ciliary dyskinesia.

reported a significant correlation between $\mathrm{LCI}$ and $\mathrm{FEV}_{1} / \mathrm{FVC}$ z-score. Still, neither finds a correlation between LCI and $\mathrm{FEV}_{1}$ $\mathrm{z}$-score. This is very surprising. Indeed, recent large data sets clearly show a very strong correlation between $\mathrm{FEV}_{1}$ and $\mathrm{FEF}_{25-}$ 75 and between $\mathrm{FEV}_{1}$ and $\mathrm{FEV}_{1} / \mathrm{FVC}$. Quanjer et $a l^{32}$ therefore strictly conclude that $\mathrm{FEF}_{25-75}$ does not add to clinical decision making.

In the current study, we found a good correlation between LCI and all spirometry parameters. These findings are indeed entirely plausible. Next, finding a correlation between LCI and CT scores was the hypothesis in previous studies and as pointed out by Rowan et al, ${ }^{29}$ PCD is a patchy disease, just as CF and
non-CF bronchiectasis. They are all marked by alterations in the mucociliary clearance mechanism and neutrophilic inflammation.

It is interesting that the CFCT score showed high scores for airway wall thickening and mucus plugging in patients with PCD. These changes are not necessarily irreversible, still depending on the site in the airways, they may cause substantial airflow obstruction, ventilation inhomogeneity or both. This may be the reason why lung function improves over time in some patients with PCD.

Limitations of this study are the retrospective inclusion of chest CT scans and the time lag between chest CT and lung 
Table 3 Correlations between lung function parameters and CT subscore parameters

\begin{tabular}{|c|c|c|c|c|c|c|}
\hline & \multirow[b]{2}{*}{ Total CFCT score (\%) } & \multicolumn{5}{|l|}{ Subscores } \\
\hline & & Bronchiectasis & $\begin{array}{l}\text { Airway wall } \\
\text { thickening }\end{array}$ & Mucus plugging & $\begin{array}{l}\text { Parenchymal } \\
\text { consolidation }\end{array}$ & $\begin{array}{l}\text { Air trapping } \\
(\mathrm{n}=24)\end{array}$ \\
\hline \multicolumn{7}{|l|}{ MBW } \\
\hline LCI z-score & $0.800 * *$ & $0.494^{* *}$ & $0.809 * *$ & 0.720 ** & $0.362^{*}$ & 0.263 \\
\hline$S_{\text {cond }} \times V_{T} z$-score & 0.276 & 0.276 & 0.120 & 0.313 & 0.043 & 0.380 \\
\hline $\mathrm{S}_{\mathrm{acin}} \times \mathrm{V}_{\mathrm{T}} \mathrm{Z}$-score & $0.361 *$ & 0.246 & 0.358 & 0.301 & -0.27 & 0.134 \\
\hline \multicolumn{7}{|l|}{ Spirometry } \\
\hline $\mathrm{FEV}_{1}$ z-score & $-0.632^{* *}$ & -0.355 & $-0.565^{* *}$ & $-0.481 * *$ & -0.298 & -0.399 \\
\hline $\mathrm{FEF}_{25-75} \mathrm{z}$-score & $-0.463 * *$ & -0.185 & $-0.518^{* *}$ & -0.31 & -0.256 & -0.368 \\
\hline $\mathrm{FEV}_{1} / \mathrm{FVC}$ z-score & -0.336 & -0.041 & $-0.493^{* *}$ & -0.269 & -0.273 & -0.078 \\
\hline
\end{tabular}

Significant correlations (Spearman correlation coefficients) are marked in bold; ${ }^{* *} p<0.01,{ }^{*} p<0.05$.

$\mathrm{LCl}$, Lung Clearance Index; MBW, multiple breath washout; $\mathrm{V}_{\mathrm{T}}$ tidal volume.
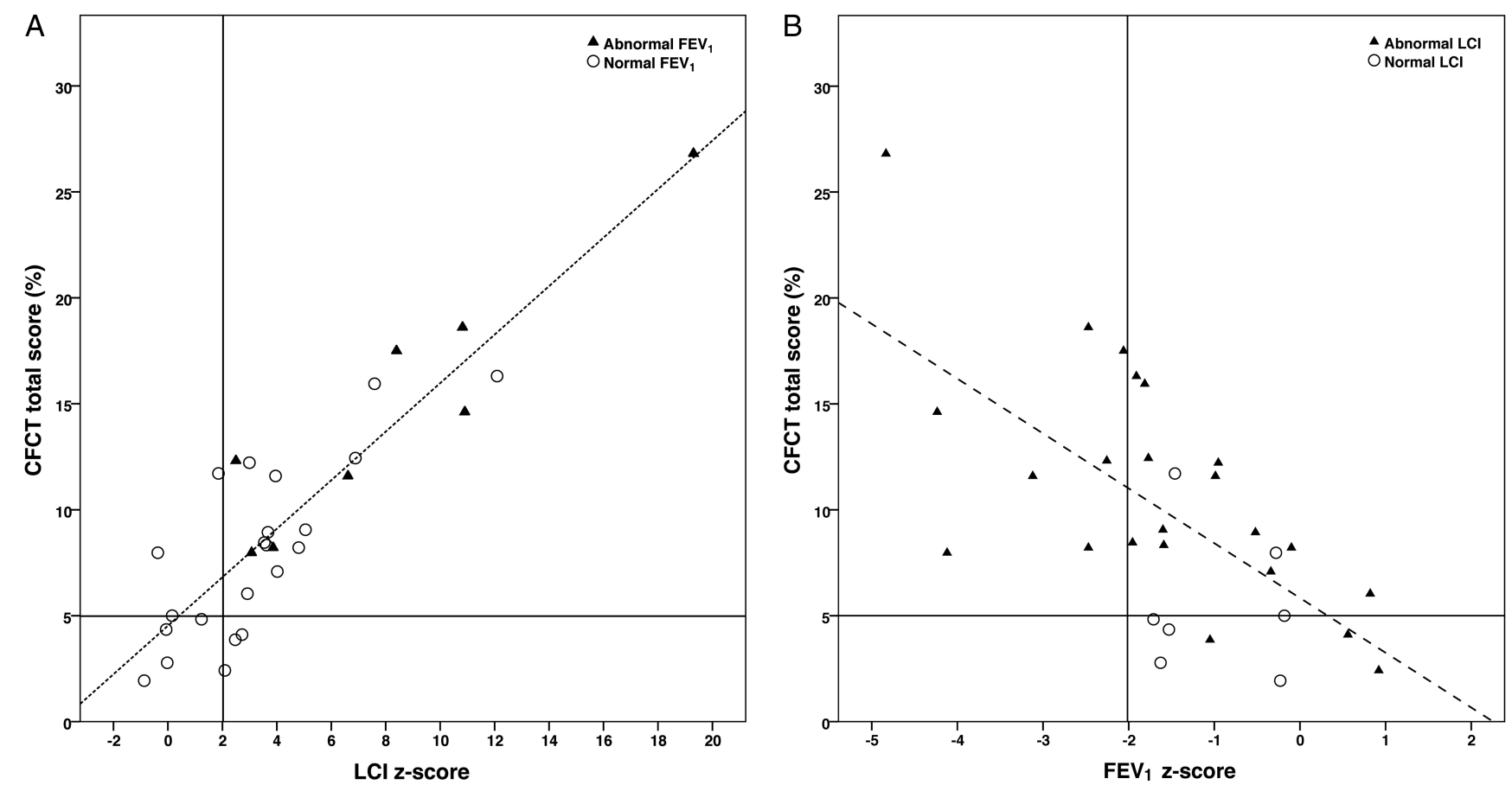

Figure 3 Correlation between functional and structural assessment of lung disease in primary ciliary dyskinesia. (A) Correlation between lung clearance index $(\mathrm{LCl}) \mathrm{z}$-score and total CFCT score. The full lines display the upper limit of normal for $\mathrm{LCl}$ and total CFCT score, the dashed line is the regression line for the correlation. (B) Correlation between $\mathrm{FEV}_{1} \mathrm{z}$-score and total CFCT score. The full lines display the lower limit of normal for $\mathrm{FEV}_{1}$ z-score and the upper limit of normal for total CFCT score, respectively. The dashed line is the regression line for the correlation.

function measurement in a few patients. Because we did not receive approval from the ethical committee to include chest CT prospectively, we used chest CT data performed in accordance with the clinically implemented protocol (chest CT every 5 years to follow evolution of structural lung damage).

In conclusion, we found that measuring LCI in patients with PCD can be of clinical importance: it is more often abnormal than $\mathrm{FEV}_{1}$ and has a greater sensitivity to detect patients with abnormal chest CT, especially in early disease. Further study of the longitudinal evolution of LCI is necessary to evaluate its usefulness as an outcome parameter in clinical trials.

Acknowledgements We thank the people from the corelab LungAnalysis, Rotterdam, The Netherlands, especially Els Van der Wiel. We are also grateful to the patients and the parents of the patients for their participation in the study.

Contributors $\mathrm{MB}$ and $\mathrm{KDB}$ conceived and designed the trial. MB enrolled the subjects and performed the experiments, chest CTs were scored by MB and WG. MJ contributed in enrolment of the subjects. MB, FLV, MP and KDB analysed the data. MB and KDB wrote the manuscript. All authors reviewed the manuscript and approved the final version.

\section{Competing interests None.}

Patient consent Obtained

Ethics approval Ethics Committee of the University Hospital of Leuven (ML5901 and amendment).

Provenance and peer review Not commissioned; externally peer reviewed.

\section{REFERENCES}

1 Boon M, Proesmans $M$, Vermeulen $F$, et al. Small airways disease in primary ciliary dyskinesia. [abstract]. Paediatr Respir Rev 2013;14(Suppl 2):S50-1.

2 Barbato A, Frischer T, Kuehni CE, et al. Primary ciliary dyskinesia: a consensus statement on diagnostic and treatment approaches in children. Eur Respir J 2009;34:1264-76.

3 Boon $M$, Jorissen $M$, Proesmans $M$, et al. Primary ciliary dyskinesia, an orphan disease. Eur J Pediatr 2013;172:151-62.

4 Kuehni CE, Frischer T, Strippoli MP, et al. Factors influencing age at diagnosis of primary ciliary dyskinesia in European children. Eur Respir J 2010;36:1248-58. 
5 Kennedy MP, Noone PG, Leigh MW, et al. High-resolution CT of patients with primary ciliary dyskinesia. AJR Am J Roentgenol 2007;188:1232-8.

6 Jain K, Padley SP, Goldstraw EJ, et al. Primary ciliary dyskinesia in the paediatric population: range and severity of radiological findings in a cohort of patients receiving tertiary care. Clin Radiol 2007;62:986-93.

7 Hellinckx J, Demedts M, De Boeck K. PCD, evolution of pulmonary function. Eur Respir J 1998;157:422-6.

8 Ellerman A, Bisgaard H. Longitudinal study of lung function in a cohort of PCD. Eur Respir J 1997;10:2376-9.

9 Marthin JK, Petersen N, Skovgaard LT, et al. Lung function in patients with primary ciliary dyskinesia: a cross-sectional and 3-decade longitudinal study. Am J Respir Crit Care Med 2010;181:1262-8.

10 Boon M, Smits A, Cuppens $H$, et al. Primary ciliary dyskinesia: critical evaluation of clinical symptoms and diagnosis in patients with normal and abnormal ultrastructure. Orphanet J Rare Dis 2014;9:11.

11 Santamaria F, Montella S, Tiddens HA, et al. Structural and functional lung disease in primary ciliary dyskinesia. Chest 2008;134:351-7.

12 Maglione M, Bush A, Montella $\mathrm{S}$, et al. Progression of lung disease in primary ciliary dyskinesia: Is spirometry less accurate than CT? Pediatr Pulmonol 2012:47:498-504.

13 Frush DP. CT dose and risk estimates in children. Pediatr Radiol 2011;41(Suppl 2):483-7.

14 Aurora P, Kozlowska W, Stocks J. Gas mixing efficiency from birth to adulthood measured by multiple-breath washout. Respir Physiol Neurobiol 2005;148:125-39.

15 Aurora P, Gustafsson P, Bush A, et al. Multiple breath inert gas washout as a measure of ventilation distribution in children with cystic fibrosis. Thorax 2004;59:1068-73.

16 Gustafsson PM, De Jong PA, Tiddens HA, et al. Multiple-breath inert gas washout and spirometry versus structural lung disease in cystic fibrosis. Thorax 2008;63:129-34.

17 Kent L, Reix P, Innes JA, et al. Lung clearance index: evidence for use in clinical trials in cystic fibrosis. J Cyst Fibros 2014;13:123-38.

18 Rowan SA, Bradley JM, Bradbury I, et al. Lung clearance index is a repeatable and sensitive indicator of radiological changes in bronchiectasis. Am J Respir Crit Care Med 2014; 189:586-92.

19 Green K, Buchvald FF, Marthin JK, et al. Ventilation inhomogeneity in children with primary ciliary dyskinesia. Thorax 2012;67:49-53.
20 Irving SJ, Ives $A$, Davies $G$, et al. Lung clearance index and high-resolution computed tomography scores in primary ciliary dyskinesia. Am J Respir Crit Care Med 2013;188:545-9.

21 Jorissen $\mathrm{M}$, Willems $\mathrm{T}$, Van der Schueren B. Ciliary function analysis for the diagnosis of primary ciliary dyskinesia: advantages of ciliogenesis in culture. Acta Otolaryngol 2000;120:291-5.

22 Roelants M, Hauspie R, Hoppenbrouwers K. References for growth and pubertal development from birth to 21 years in Flanders, Belgium. Ann Hum Biol 2009;36:680-94

23 Robinson PD, Latzin P, Verbanck $S$, et al. Consensus statement for inert gas washout measurement using multiple- and single- breath tests. Eur Respir $J$ 2013:41:507-22.

24 Miller MR, Crapo R, Hankinson J, et al. General considerations for lung function testing. Eur Respir J 2005;26:153-61.

25 Quanjer PH, Stanojevic S, Cole TJ, et al. Multi-ethnic reference values for spirometry for the 3-95 year age range: the global lung function 2012 equations. Eur Respir $J$ 2012;40:1324-43.

26 Brody AS, Klein JS, Molina PL, et al. High-resolution computed tomography in young patients with cystic fibrosis: distribution of abnormalities and correlation with pulmonary function tests. J Pediatr 2004;145:32-8.

27 Houltz B, Green K, Lindblad A, et al. Tidal N2 washout ventilation inhomogeneity indices in a reference population aged 7-70 years. [abstract]. Eur Respir J 2012;40 (Suppl 56):P3797.

28 Jensen R, Stanojevic S, Gibney K, et al. Multiple breath nitrogen washout: a feasible alternative to mass spectrometry. PLoS One 2013;8:e56868.

29 Rowan S, Horsley A, Bradley J, et al. Reply: lung clearance index in primary ciliary dyskinesia and bronchiectasis. Am J Respir Crit Care Med 2014;189: 1148-9.

30 Irving SJ, Davies JC, Alton EW, et al. Lung clearance index in primary ciliary dyskinesia and bronchiectasis. Am J Respir Crit Care Med 2014;189:1147-8.

31 Roberts HR, Wells AU, Milne DG, et al. Airflow obstruction in bronchiectasis: correlation between computed tomography features and pulmonary function tests. Thorax 2000;55:198-204.

32 Quanjer PH, Weiner DJ, Pretto JJ, et al. Measurement of FEF25-75\% and FEF75\% does not contribute to clinical decision making. Eur Respir J 2014;43:1051-8. 